\title{
La transición virtual
}

Por Gustavo González Rodríguez

En 1989 Internet fue abierta a los usuarios comerciales en los Estados Unidos. Se tendió así el primer eslabón de una nueva cadena que se propagaría de inmediato a todo el mundo. La "red de redes", que había tenido su partida de nacimiento en 1983 como hija putativa del Arpanet, sentaba las bases de lo que hoy se conoce como la "nueva economía".

En 1983 comenzaron en Chile las protestas por el retorno a la democracia y en 1989 el proceso de transición daba sus primeros y balbuceantes pasos tras la derrota de Augusto Pinochet en el plebiscito presidencial del 5 de octubre de 1988. Ese mismo año, la globalización cobró partida de nacimiento con la caída del Muro de Berlín, que puso fin al esquema bipolar de la guerra fría.

Con el colapso de los socialismos reales se terminó de configurar un nuevo orden mundial, caracterizado en lo político por la unipolaridad y en lo económico por la expansión sin fronteras y sin control de los capitales transnacionales. Estos procesos no habrían sido posibles sin la revolución científico-tecnológica que propulsó los avances sin precedentes de la telemática, como gustan algunos llamar a la alianza entre las telecomunicaciones y la informática.

La transición chilena tiene entonces lugar en este escenario de consagración del ciberespacio y la virtualidad como nuevos "territorios" para las comunicaciones y la expresión de la ciudadanía. Un escenario que, bajo esos parámetros, desafía las formas y conceptos tradicionales del ejercicio periodístico, en términos de que reformula profundamente la relación entre los medios, como emisores, y el público, como expresión genérica de los hasta ahora pasivos receptores.

El fenómeno mundial, que tiene como principal ícono o palabra mágica a Internet, no es, como se sabe, homogéneo en todo el planeta. Más bien, tiende a consagrarse como la expresión más actual de las desigualdades entre ricos y pobres, ya sea en los ranking de países o al interior de éstos, sean industrializados o subdesarrollados. Chile ocupa una posición marginal pero a la vez promisoria en la "red de redes", de acuerdo a los datos sobre acceso a Internet. Pero el problema no es solo cuantitativo. En lo que atañe a las comunicaciones y a la necesaria renovación del periodismo es también y fundamentalmente cualitativo. El presente trabajo pretende aportar algunas reflexiones en esa dirección.

\section{Del teletipo a la sociedad del conocimiento}

Muchas de las agencias y corresponsales que en la noche del 5 de octubre de 1988 lanzaran al mundo la noticia de la derrota de Pinochet en el plebiscito presidencial, lo hicieron con teletipos conectados a líneas telefónicas, ya fueran conmutadas o dedicadas (punto a punto), provistos de dispositivos "inteligentes" incorporados a computadores AT, con cursores que transmitían el texto a medida que se deslizaban por los dígitos grabados en la pantalla del monitor. Otros aparatos hacían la transmisión a través de un lector mecánico de una cinta perforada en que letras y números se ponchaban (un barbarismo derivado del inglés punch en la jerga de los teletipistas) según el ingenioso sistema del punto y raya que en el siglo XIX dio nacimiento al lenguaje morse del telégrafo.

Para entonces, la tecnología había dejado atrás los viejos y ruidosos teletipos que transmitían a una velocidad de 40 baudios para multiplicarla a un estándar de 200 baudios, lo cual rompió con la referencia mecanográfica para estos efectos. Hoy, los modem digitales alcanzan velocidades de transmisión más rápidas que el pensamiento o la luz y tanto los teletipos, como máquinas, y los teletipistas, como oficio, son objetos de museo. 
"Nueva economía" y progreso tecnológico son dos variables clave en la incorporación de los países y las sociedades a Internet, en un proceso que en el caso de Chile coincide con una transición para muchos incompleta e inconclusa en su vertiente política y cuestionable en sus efectos sociales y culturales.

El tercer gobierno de la Concertación por la Democracia se propone encaminar al país hacia la sociedad de la información, según las recomendaciones emanadas en 1999 de la Comisión Presidencial sobre "Nuevas tecnologías de información y comunicación"(1).

En su primer mensaje ante el Congreso como Presidente de la República, el 21 de mayo de 2000, Ricardo Lagos proclamó que "el Estado de Chile se pondrá a la vanguardia mundial en conectividad". Entre los planes de su mandato está la creación de una "ventanilla electrónica única" para las relaciones entre los ciudadanos y el Estado, la habilitación de una red de enlace cultural y el equipamiento de unas 100.000 pequeñas y medianas empresas con computadores y conexión a Internet(2).

En esa línea, el 30 de agosto de 2000 la Corporación de Fomento de la Producción (Corfo) convocó a licitación pública para adquirir los 100.000 computadores que se ofrecerán en condiciones crediticias favorables a sostenedores de colegios subvencionados y a micro y pequeños empresarios. Del mismo modo, se cuenta a través del Servicio de Cooperación Técnica (Sercotec) con una red de Infocentros que, en octubre de este año, abarcaba ya a 24 ciudades, desde Arica hasta Punta Arenas.

La incorporación de las TIC (tecnologías de la información y la comunicación) es una tarea urgente y estratégica en Chile, no sólo para el Estado, sino también para los agentes económicos y los actores sociales. Es un imperativo para un país que ingresó en la transición política adelantándose al resto de América Latina en la cristalización de las reformas estructurales de inspiración neoliberal y que ahora tendría en la "nueva economía" las posibilidades de fortalecer y consolidar ese modelo para no perder el liderazgo latinoamericano. Una posibilidad que quita el sueño a los empresarios y a la clase política.

Desde otro ángulo, tal vez más trascendental, la democratización del acceso a las TIC es una de las rutas posibles para avanzar en la transición hacia un sistema político más participativo, que cuestione no sólo los enclaves autoritarios heredados de la dictadura sino también la inequidad socioeconómica y las manifestaciones de intolerancia cultural que aparecen como obstáculos para construir un Chile integrado en el pluralismo y la diversidad.

Los afanes modernizadores que buscan llevar al país hacia la sociedad de la información son observados con escepticismo, desconfianza y hasta con sorna por los sectores marginados y por los desencantados de la transición. Dirigentes de la masiva toma de terrenos en Peñalolén reivindican un ejercicio democrático local y directo al tiempo que hablan peyorativamente de la "izquierda de Internet"(3).

No obstante las voces disonantes, el concepto de sociedad de la información se propaga asociado al crecimiento de Internet, sobre la base de que los avances telemáticos deben propiciar un flujo expedito y universal de mensajes de todo tipo entre los seres humanos.

Para algunos expertos, como Roberto Savio(4), es incorrecto hablar de sociedad de la información, ya que el concepto de información remite a una relación vertical entre el emisor y una masa de receptores, mientras que Internet permite flujos de ida y vuelta entre emisores y receptores, con intercambio de sus respectivos papeles. Por ello, sería más acertado legitimar a las TIC como el instrumento para construir una sociedad de la comunicación.

En estos últimos años, regidos por avances realmente vertiginosos en las TIC y su aplicación práctica, se acuñó un nuevo paradigma virtual: el de la sociedad del conocimiento. Internet, en rigor, ya no es únicamente la gran telaraña que posibilita la circulación sin fronteras de mensajes, informaciones y operaciones de negocios. Es también un banco infinito de datos y 
saberes. Pero, todavía más que eso, permite aplicaciones a distancia de programas informáticos que satisfacen tanto necesidades rutinarias como excepcionales de los seres humanos. La capacitación y la educación pueden multiplicar su alcance, mientras los agricultores y las comunidades que residen en áreas inseguras podrán tener acceso en tiempo real a los informes del clima con sus computadores conectados a sitios en que se depositan los datos de satélites meteorológicos. Lo mismo se aplicará, mejor dicho, se está aplicando, en el resguardo de las poblaciones amenazadas por el deterioro de la capa de ozono en las regiones australes. Una de las expresiones más interesantes de esta renovada dimensión, según Cepal, está en la telemedicina, que se encamina a revolucionar las prácticas tradicionales de atención de salud con un positivo efecto hacia las áreas menos desarrolladas y las poblaciones en estado de pobreza(5).

\section{La "brecha digital"}

Una de las paradojas de Internet es su capacidad de maravillar con avances científicos y tecnológicos que parecen ejercicios de ciencia-ficción, contrastada con los abismos que se van configurando a diario en el acceso a estos avances. La "brecha digital" entre países ricos y pobres, y entre ricos y pobres al interior de las sociedades, es un fenómeno en constante crecimiento y que marca la desigualdad entre áreas industrializadas y subdesarrolladas con más intensidad que otros parámetros aplicables en las relaciones Norte Sur(6).

En su Informe sobre Desarrollo Humano 1999, dedicado a "La mundialización con rostro humano", el Programa de Naciones Unidas para el Desarrollo (Pnud) señaló: "Comprar un computador costaría al habitante medio de Bangladesh el ingreso de más de ocho años, en comparación con el sueldo de un mes solamente que costaría al estadounidense medio"(7).

El mismo informe consignó, con base en cifras de 1998, que 108 de cada 1.000 habitantes de Finlandia son anfitriones o navegantes en Internet. En los Estados Unidos la relación era de 88,9 por 1.000 habitantes y en Chile de 2,07. La tasa chilena era superada en América Latina solo por Uruguay, con 5,02. En Haití, el país más pobre de la región, era de 0,02.

Las estadísticas sobre la "brecha digital" señalan que en marzo de 2000 había en el mundo unos 304 millones de usuarios de Internet, de los cuales $45 \%$ se concentraba en los Estados Unidos y Canadá, 27 \% en Europa y 23 \% en el Asia-Pacífico. En América Latina estaba 3,5\% de los usuarios, mientras $1,5 \%$ se dividía entre África y el Medio Oriente. Antes de fin de año el número de usuarios mundiales sobrepasaría los 350 millones de personas, con una tasa elevada de crecimiento entre los latinoamericanos(8).

En lo que respecta específicamente a Chile, un informe de la Subsecretaría de Telecomunicaciones, difundido a comienzos de octubre de 2000, mostró un crecimiento de $189 \%$ de los usuarios de Internet, desde 700.000 en diciembre de 1999 hasta dos millones en esa fecha. Esto significa que $13 \%$ de los chilenos son navegantes de la red, lo cual coloca al país en una posición avanzada en América Latina, detrás de Brasil, junto a México y antes que Argentina.

Lo cierto es que las cifras varían constantemente, al ritmo acelerado no solo de la adquisición de computadores, sino también de nuevas ofertas de conectividad y de la incorporación de adelantos en las telecomunicaciones, como la fibra óptica y el acceso de banda ancha a través del cable coaxial de televisión.

Pero a la vez estos datos parecen jugar el papel de un premio de consuelo en un mundo virtual donde los habitantes del otrora llamado Tercer Mundo, incluyendo a los latinoamericanos, siguen siendo marginales. No en vano, el referente de los avances sigue siendo Estados Unidos, país que sólo en cuatro años completó 50 millones de personas conectadas a Internet. Para que ese mismo número de estadounidenses adoptara la radio como sistema de información debieron transcurrir 38 años, 13 años para que 50 millones se conectaran a la televisión y 16 años para que la misma cantidad de población tuviera un computador personal(9). 
Las desigualdades de este mundo digital se muestran también en el hecho de que $75 \%$ de los sitios en Internet usan como idioma exclusivamente el inglés. Le siguen en importancia los sitios en alemán, japonés y francés. Sólo $3 \%$ del total de sitios está en español, pese a que este idioma es hablado por unos 400 millones de personas, es decir, por alrededor de $8 \%$ de la población mundial.

Matthew Yeomans advierte que $88 \%$ de los usuarios de Internet vive en países industrializados, los cuales representan $15 \%$ de la población mundial. El Asia centromeridional (donde están Blangladesh, India, Pakistán) alberga a $20 \%$ de la población del planeta y a apenas $1 \%$ de los cibernautas. Africa, a su vez, tiene 739 millones de habitantes, apenas 14 millones de líneas telefónicas y solamente un millón de usuarios de Internet(10).

\section{Nueva economía y nueva comunicación}

A 17 años del nacimiento de Internet y 11 del inicio de la "nueva economía", el ciberespacio ha sido ganado fundamentalmente para los negocios, desde el punto de vista de las aplicaciones más atractivas y de mayor crecimiento y rentabilidad en la red de redes. Las transacciones comerciales y financieras están ya clasificadas a partir de sus agentes y hoy resulta familiar leer en la prensa sobre operaciones B2B (business to business) y B2C (business to consumers), según se trate de transacciones entre empresas o de éstas con consumidores. Un menor desarrollo y figuración alcanzan las operaciones C2B (consumers to business) o C2C (consumers to consumers), en las cuales la iniciativa está del lado de los consumidores.

No corresponde citar aquí las múltiples manifestaciones del embrujo del comercio virtual, con casos ya antológicos de emprendedores que crearon prácticamente desde la nada, "apenas" con mucha imaginación y un buen software, portales de negocios que luego vendieron en millones de dólares y cuyas acciones se cotizan a precio de oro en el Nasdaq, la bolsa electrónica de Nueva York.

Lo que interesa rescatar de este cuadro es el hecho de que el crecimiento y auge de Internet descansa en gran medida en su legitimación como instrumento para los negocios de todo tipo, desde lícitos hasta ilícitos. En este desarrollo se reproducen de alguna manera las modalidades tradicionales de la economía de mercado, con una tendencia a la concentración. El éxito de un joven y dinámico emprendedor se legitima cuando logra que su portal sea adquirido por una gran transnacional. Ello, ocurre tanto en el mundo del comercio y de las finanzas virtuales, como en el de los multimedios informativos, de entretenimiento y cultura.

Internet es así un mar generoso para la navegación de la "nueva economía", que es nueva sobre todo porque amplía los espacios y reduce los tiempos para los negocios, pero no porque subvierta a fondo las relaciones imperantes en el actual orden globalizado. $Y$ es que el mundo virtual no sustituye al mundo real, en el cual las corporaciones son más poderosas que las entidades representativas de la sociedad civil y en particular que las organizaciones sindicales o de consumidores, supuestas contrapartes o interlocutoras del empresariado y los gobiernos.

Las dimensiones de la información y la comunicación de masas son también sacudidas por la telemática, en tanto Internet cambia radicalmente los mecanismos de relación entre el público y los medios. El hipertexto, los multimedios, las posibilidades de interactividad y de segmentación, la "periodicidad" o actualización constante, son atributos de las TIC que plantean una nueva alfabetización de los seres humanos para ingresar a la sociedad del conocimiento.

Estamos en una "nueva comunicación", pero al igual que la "nueva economía", ésta no garantiza por la sola influencia de las tecnologías avanzadas una democratización de las sociedades.

El artículo ya citado de Roberto Savio alude al debate de las décadas del 70 y 80 sobre el nuevo orden informativo internacional y el subsiguiente planteamiento del Nomic (nuevo 
orden mundial de la información y la comunicación), impulsado por el célebre informe de la Comisión MacBride en el seno de la Unesco (Organización de Naciones Unidas para la Educación, la Ciencia y la Cultura)(11). El debate se distorsionó a partir de la posición ideologizante con que gobiernos de países industrializados, en especial Estados Unidos con Ronald Reagan y el Reino Unido bajo Margaret Thatcher, amén de organizaciones empresariales como la Sociedad Interamericana de Prensa (SIP), se opusieron a las recomendaciones de la comisión, que apuntaban a corregir un problema básicamente estructural: el desequilibrio de los flujos informativos entre el Norte y el Sur.

Los años y la globalización han demostrado que los desequilibrios Norte-Sur no disminuyen. Aún más, se acentúan en las áreas más pobres y se expanden incluso a las sociedades industrializadas a la grupa de fenómenos como las migraciones y la exclusión social. La "brecha digital", que no es sino una expresión más actual y más dramática de la brecha del desarrollo, indica que en Internet parafraseando la definición que alguna vez se hizo de la Organización de Estados Americanos todos somos iguales, pero algunos son más iguales que otros.

Una visita a Mundo Latino (www.mundolatino.org) u otro portal de prensa muestra una presencia marginal, en términos de medios digitales, de países como Haití o Guatemala. En el ámbito de la prensa electrónica, la realidad latinoamericana sigue siendo retratada y analizada fundamentalmente con ojos anglosajones, al igual que en la prensa tradicional. En la "crisis" de precios del petróleo, desatada este año 2000, la visión de los países productores es minimizada y recogida bajo los cánones de los países industrializados. Guste o no, los grandes diarios de papel son también los grandes diarios electrónicos.

\section{Medios y comunicación alternativa}

En términos estructurales, el diagnóstico en que se basó la propuesta del Nomic a comienzos de los años 80 sigue siendo válido hoy. Pero el mundo actual no es el mismo de hace dos décadas y ello también se refleja en la prensa. La globalización es también consecuencia de la existencia de problemas o desafíos comunes para toda la humanidad que desbordan las fronteras nacionales o regionales.

La temática sobre derechos humanos, desde los aspectos jurídicos ilustrados con el "caso Pinochet", hasta las luchas a favor de la infancia, las minorías étnicas y sexuales y en pro de la igualdad de géneros, está instalada en la agenda de los medios gracias a las campañas de las organizaciones de la sociedad civil y de las Naciones Unidas. Lo mismo puede decirse de la preocupación por el deterioro de la capa de ozono, el efecto invernadero, la deforestación de la Amazonía y otros temas ambientales.

Es ya casi un lugar común señalar que, en la era de la globalización, cobran relieve simultáneamente lo universal y lo local, en perjuicio de lo nacional. El tradicional Estadonación, sobre todo en los países subdesarrollados, es a la vez promotor, garante y víctima del mundo globalizado. Esto posibilita fenómenos críticos, como la expansión especulativa y descontrolada de las grandes masas de capitales financieros, pero a la vez abre positivamente espacios de expresión y de construcción de alianzas internacionales para sectores sometidos culturalmente por estos mismos estados nacionales(12).

La prensa y la comunicación alternativas acompañan estos procesos con un grado de alcance multiplicado gracias a las TIC e Internet. En el caso específico de la transición chilena, esto ha permitido que los poderes del Estado sean puestos frecuentemente bajo una suerte de vigilancia crítica, tanto a nivel local como internacional, lo cual es saludable para la democracia.

Durante los 302 días del arresto de Pinochet en Gran Bretaña, los mail distribuidos profusamente por el Piquete de Londres y otras organizaciones de chilenos en el exilio, así como el acceso instantáneo a sitios de organizaciones como Amnistía Internacional y Human Rights Watch, fueron un contrapeso significativo a la información oficial del gobierno de 
Eduardo Frei. Las redes ambientalistas y las organizaciones no gubernamentales (ONG) no solo difundieron al mundo su rechazo al proyecto forestal Cascada en Puerto Montt, sino que además lograron que fuera adoptado como uno de los emblemas de las masivas protestas de la sociedad civil en torno a la conferencia ministerial de la Organización Mundial de Comercio en Seattle en diciembre de 1999.

A despecho de las posiciones contestatarias anti-Internet, como la ya comentada del dirigente de la toma de Peñalolén, lo cierto es que el ciberespacio ofrece, entre sus múltiples usos, la posibilidad de diseminar planteamientos y experiencias en escala inimaginable hace algunos años para las organizaciones de la sociedad civil. La comunicación de base se potencia y pasa a ser así tanto una alternativa como un complemento, según el caso, a la prensa en sus diferentes soportes, ya sean tradicionales o multimediales.

La Asociación para el Progreso de las Comunicaciones (www.apc.org) es uno de los ejemplos más notables de la creación a escala mundial de una red de agencias y otros medios alternativos, con intercambios de información que van en beneficio de las ONG y otras expresiones de la sociedad civil. El ejemplo de la APC encuentra réplicas locales en muchos países, que a su vez a través de Internet establecen contactos internacionales.

En este Chile en eterna transición resulta significativo que uno de los primeros diarios en Internet fuera La Época, cuya edición digital desapareció con la versión impresa en lo que fue uno de los episodios más dolorosos y controvertidos de la política comunicacional levantada por la Concertación por la Democracia.

Otro de los ejemplos pioneros en el país es Chile Noticias (www.chilenoticias.cl), un sitio creado a mediados de la década de los 90 por estudiantes de la Escuela de Periodismo de la Universidad de Santiago de Chile, que difunde tanto información propia como de otros medios y que fue inicialmente concebido para los chilenos residentes en el exterior. En 1998, otros estudiantes, vinculados a la Escuela de Periodismo de la Universidad de Chile y a otras unidades de esta misma universidad crearon Chileradio (www.chileradio.cl), una expresión también novedosa como una de las primeras emisoras exclusivamente digitales.

Un medio virtual destacado es El Mostrador (www.elmostrador.cl) que en el año 2000 surge como un periódico on line de actualización permanente, para competir con éxito, en cuanto a calidad y rapidez informativa, con los medios tradicionales y sus ediciones virtuales, como $\mathrm{El}$ Mercurio y La Tercera.

Según Open Chile, en marzo de 2000 existían en el país 206 medios electrónicos, incluyendo aquellos nacidos exclusivamente en Internet, como Chile Noticias, Chileradio y El Mostrador, y aquellos que desde una matriz convencional crearon sus sitios en la red. La cifra incluye 45 diarios, 79 revistas, 17 canales de televisión y sitios sobre programación televisiva, 38 emisoras y cuatro portales informativos(13).

Los bajos costos de la habilitación de un sitio web posibilitan que en Internet se creen medios de comunicación con un capital mínimo. Los diarios y revistas virtuales de los más diversos orígenes colocados en la "red de redes" se abstraen de la circulación o número de ejemplares como mecanismo legitimador de su existencia. En el ciberespacio, el alcance de un medio se determina por las visitas a su sitio y por el impacto de sus contenidos, reflejado a menudo en los medios de prensa escritos, antecedente que a la vez debería constituirse en el factor para vender banners publicitarios que generen ingresos.

Pero, salvo algunos casos de portales internacionales de prensa electrónica y otros servicios que por su naturaleza y llegada son atractivos para la publicidad, los medios electrónicos están lejos todavía de ser un buen negocio. Ni en Chile ni en los Estados Unidos se conocen casos de medios digitales que generen grandes utilidades. La inversión publicitaria, que crece día a día y alcanza dimensiones millonarias comparables a la inversión productiva y en educación, sigue privilegiando los medios tradicionales, en especial la televisión. 
Este es tal vez el testimonio más certero de las limitaciones que las desigualdades sociales imponen a la expansión de Internet y, por consiguiente, a la comunicación y a la prensa digitales. El Informe de Desarrollo Humano del Pnud de 1999 señaló que el 20 \% de la población mundial que vive en los países más desarrollados posee $74 \%$ de las líneas telefónicas, el medio básico de ingreso a las sociedades de la información y el conocimiento(14).

A comienzos de los años 90 la relación de líneas telefónicas en los países industrializados era de 50 por cada 100 habitantes. En América Latina era de 11 cada 100. Durante la década hubo una expansión significativa de la telefonía, lo cual permitió recuperar terreno en este sentido a varios países. Entre ellos Uruguay, con 30 líneas cada 100 habitantes, y Argentina, Chile y Costa Rica, cada uno con una media de 22 cada 100.

\section{Mercado, políticas públicas y libertad de expresión}

A comienzos de noviembre de este año 2000, la Telefonica, principal empresa proveedora de servicios de telefonía en Chile, anunció una reducción de 50 por ciento en sus programas de instalación de líneas domiciliarias, arguyendo que las políticas tarifarias fijadas por las autoridades le impedían cumplir sus metas originales.

La privatización de las empresas de servicios, entre ellas las de telecomunicaciones, es presentada como el factor fundamental que posibilitó la expansión de la telefonía en Chile. La deficiencia del estatismo fue sustituida ventajosamente por la asignación de recursos a través del mercado, de acuerdo al discurso dominante. Así, se llega a atribuir al mercado una mayor capacidad que el Estado para satisfacer demandas sociales y promover el progreso de las comunidades.

Este discurso es puesto en tela de juicio, no solo por las presiones tarifarias de empresas cuasi monopólicas como la Telefónica, sino también por la propia realidad latinoamericana. Uruguay, el país de mayor densidad de líneas telefónicas por habitante en la región, nunca privatizó Antel, su empresa de telecomunicaciones, porque esa posibilidad fue rechazada por la ciudadanía, en el ejercicio democrático de sus derechos a través de un plebiscito. Costa Rica, cuyo capital de líneas es similar al de Chile, mantiene igualmente estatizada la telefonía.

A contrapelo del dogma neoliberal hay que advertir que el mercado no es un buen distribuidor de oportunidades de cara a la sociedad de la información. Cepal(15) consigna que los países nórdicos, los más avanzados en términos de conectividad a Internet, vienen aplicando exitosamente políticas públicas para dar acceso a sus poblaciones a la sociedad del conocimiento. Los estímulos tributarios para la compra de computadores personales, el equipamiento computacional masivo de establecimientos de educación, la instalación de infocentros de uso gratuito para sectores de menores ingresos y pequeñas y medianas empresas son parte de un vasto menú de opciones para democratizar y hacer crecer los porcentajes de conectividad al ciberespacio.

Las propuestas del gobierno de Ricardo Lagos buscan apuntar en esa dirección, aunque tal vez se requeriría de iniciativas más audaces que permitan sortear las presiones tarifarias y otras barreras de la "libre" competencia. Cepal exhorta a la adopción de políticas públicas orientadas en cuatro líneas: a) corregir los efectos adversos de las reformas estructurales (de corte liberal), b) corregir las fallas del mercado, c) profundizar los esfuerzos de innovación y difusión tecnológica y c) favorecer una mayor eficiencia y equidad en la transición hacia la sociedad del conocimiento.

Tales recomendaciones no aparecen sólo válidas para la transición hacia la "nueva economía", sino también hacia la "nueva comunicación". Pero en este, como en otros aspectos de la transición chilena, la llamada clase política muestra escasa visión de futuro. Los resabios del autoritarismo se muestran de cuerpo entero en la labor legislativa de estos últimos años en torno a Internet. No se conoce de iniciativas parlamentarias que amplíen el acceso a la red o 
estimulen su uso como instrumento de comunicación por parte de la sociedad civil. En cambio, ya se han aprobado leyes de regulación, como la que castiga el delito informático y la que protege los datos personales, mientras está en trámite en esta fecha (noviembre de 2000) un proyecto sobre documentos electrónicos.

En un país regido por las censuras de todo tipo, Internet ha sido una válvula no sólo para la expresión de sectores culturalmente y socialmente segregados, sino también un medio para eludir normas legales arbitrarias que atentan contra las libertades de expresión y de información. En 1999 la versión digital del diario La Tercera sentó dos hitos importantes en ese sentido, al abrir sitios en los Estados Unidos para mantener a sus lectores al tanto de la "Operación Océano", luego de que un juez dictara prohibición de informar sobre este caso de narcotráfico, y, segundo, para dar a conocer el censurado y perseguido "Libro negro de la justicia chilena", de Alejandra Matus.

Pero también hay ejemplos de censura de poderes económicos en la red. El 3 de noviembre de 2000 se puso abrupto fin, con dos meses de anticipación, al proyecto "Vivonline.com", del ex estudiante de Periodismo Enrique Piracés. Más allá de las razones de mercado aducidas por Ilatin Holdings, auspiciadora de la iniciativa, otras versiones indicaron que la cancelación del proyecto se debió a los vínculos de Piracés con Chileradio y a la difusión que esta emisora virtual hace de las activiades de la Comisión Funa, organización de denuncia pública de ex agentes represivos y personalidades vinculadas a violaciones de los derechos humanos. Como se sabe, en octubre de 2000 fue "funado" el empresario Ricardo Claro, uno de los principales accionistas de Ilatin Holdings.

\section{Ejemplos actuales e interrogantes a futuro}

Internet será un espacio libertario y participativo en la medida en que la sociedad sea más libertaria y participativa. Los medios electrónicos ofrecen un amplio potencial de interactividad para horizontalizar la comunicación con el público. Los foros, encuestas y "chateos" abren al público espacios vedados hasta ahora en los diarios tradicionales, donde las cartas de lectores son un pálido remedo de participación.

Quien ingrese a los foros de las ediciones digitales de El Mercurio y La Tercera podrá advertir, entre otros fenómenos interesantes, la participación significativa en número de chilenos residentes en el exterior. La comunidad exiliada, tan desatendida por la transición chilena, encuentra en Internet una instancia de expresión acerca de temas de interés en el país y entrega opiniones que evidencian una visión crítica de esta misma transición.

Los foros son asimismo una suerte de retrato en crudo de la sociedad. Al no pasar por el "filtro" de la edición, las opiniones de los cibernautas los reflejan a éstos de cuerpo entero, incluso con sus faltas de ortografía, su lenguaje y sus complejos. En los foros de El Mercurio, por ejemplo, es posible encontrar textos que por su grado de informalidad y vulgarización en el lenguaje jamás encontrarían cabida en las columnas impresas del decano de la prensa nacional.

Las posibilidades de desarrollo de los medios digitales son infinitas. Pese a su multiplicación en Chile, aún se está en fases muy elementales que plantean desafíos en cuanto a su calidad. La nueva alfabetización, para algunos "nueva retórica", que acompaña a Internet tiene expresiones concretas en el hipertexto de los mensajes digitales. Como dijo Lluis Codina, la interacción entre el cibernauta y el medio digital está en la capacidad de este último, como sistema de comunicación, de suministrar "diferentes respuestas de acuerdo a las diferentes acciones del usuario"(16).

Los enlaces, vínculos e hipervínculos deben posibilitar tantos "linkeos" como intereses del lector que se aproxima a un tema. La intermediación del periodista del medio electrónico no estará sólo en su capacidad de recrear un acontecimiento o explicar un tema a los lectores, sino también en darles a éstos la posibilidad de acceder a un vasto abanico de información 
complementaria, ya sea textual o gráfica, desde el banco de datos, el informe de los expertos, las fotografías, mapas y un largo etcétera, así como a otras fuentes periodísticas.

El desafío consiste, en última instancia, en construir ciudadanía a través de Internet. Y esta es una tarea que convoca tanto a los poderes del Estado, como a los medios y a la sociedad civil. Desde la universidad, en tanto, estamos convocados a repensar la enseñanza de la comunicación social y el periodismo, en un terreno que, por ahora, contiene más interrogantes que respuestas.

1 "Chile hacia la sociedad de la información", Comisión Presidencial NUEVAS TECNOLOGíAS DE INFORMACIÓN Y COMUNICACIÓN. Presidencia de la República, 1999.

2 Mensaje Presidencial, 21 de mayo de 2000.

3 Véase, por ejemplo, La Toma, entrevista publicada en la revista Punto Final № 475, julio de 2000.

4 Véase, al respecto, su artículo Internet, el Príncipe y el Mercader, publicado en este mismo número de COMUNICACIÓN Y MEDIOS.

5 América Latina y el Caribe en la transición hacia una sociedad del conocimiento. Una agenda de políticas públicas. Comisión Económica para América latina y el Caribe, CEPAL. LC/l.1383. Junio de 2000. Disponible también en www.eclac.cl.

6 Cepal. Op. Cit.

7 Informe sobre Desarrollo Humano 1999, PNUD. Pag. 62. Ediciones Mundi-Prensa, España, 1999.

8 CEPAL. Op. Cit.

9 MEEKER y PEARSON, 1998. Citado por Cepal. Op. Cit.

10 Citado por FORD, Anibal en El G-8, Okinawa y la 'digital divide' o la utopia comunicacional como sistema de dominio, publicado en DIÁLOGOS DE LA COMUNICACIÓN 59-60, revista de Felafacs, octubre 2000, Lima, Perú.

11 Muchas voces, un mundo. Informe de la Comisión MacBride, 1980. Editorial Fondo de Cultura Económica. México.

12 El tema está desarrollado con más amplitud por el mismo autor en Conflictos indígenas, globalización, prensa y estados nacionales. El caso de Chile. DIÁLOGOS DE LA COMUNICACIÓN 59-60.

13 Citado por DONOSO ASTETE, Fernando en Internet y el desafío del periodismo digital. MEMORIA DE TÍTULO, Escuela de Periodismo Universidad de Chile, septiembre de 2000.

14 PNUD. Op. Cit. Pag. 3.

15 Ver CEPAL, Op. Cit.

16 CODINA, Lluis: La prensa electrónica en Internet y el futuro de los medios de comunicación, en INFORMATION WORLD en español, abril de 1996. Citado por Fernando Donoso Astete, Op. Cit. 